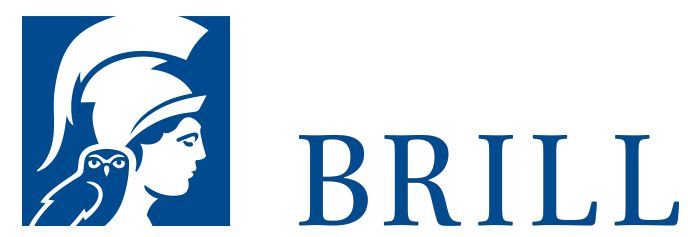

\title{
Anwendungsbezogene Grundlagenforschung mit Pilzen
}

Am Beispiel des Penicillin-Antibiotikaproduzenten Penicillium chrysogenum wird in diesem Artikel die Verknüpfung von Grundlagenforschung und angewandter Forschung aufgezeigt. Bei diesem industriell genutzten Hyphenpilz konnten vor kurzem zum ersten Mal Sexualprozesse beobachtet werden, die von genetischen Faktoren abhängig sind. Dabei wurde entdeckt, dass diese genetischen Faktoren auch die Antibiotikaproduktion wesentlich beeinflussen. Beispielhaft wird somit die Grundlagenforschung mit der anwendungsbezogenen Fragestellung verknüpft.
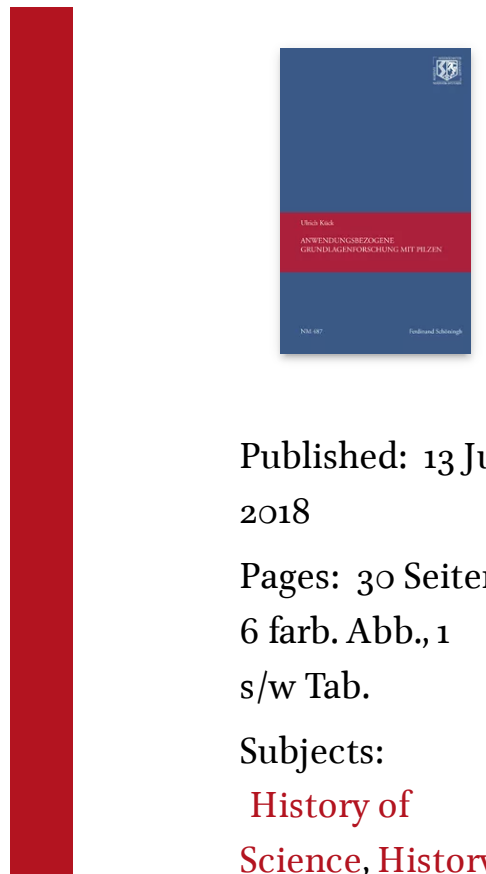

Published: $13 \mathrm{Jul}$ 2018

Pages: 30 Seiten, 6 farb. Abb., 1 s/w Tab.

Subjects:

History of

Science, History

Publisher: Brill |

Schöningh

Series:

Nordrhein-

Westfälische

Akademie der

Wissenschaften und der Künste -

Naturwissenschaften und Medizin,

Volume: 487

Paperback

ISBN: 978-3-

506-79236-5

Price:

[USS] \$17.00 
Please send your order to: Brockhaus/Commission Tel: +49(o)71 541327 9216 | E-Mail: brill@ $\underline{\text { brocom.de }}$

For questions please contact: Brill Deutschland GmbH

Wollmarktstraße 115 | 33098 Paderborn | Germany

Tel: +49 (o)5251 69975 o | E-Mail: sales@brill.com. 